\title{
Pengembangan Lembar Kerja Siswa (LKS) Fisika Berbasis Contextual Teaching and Learning (CTL) Untuk Meningkatkan Prestasi Belajar Siswa
}

\author{
Muadin Wasis Saeful Bahri ${ }^{1)}$, Widodo ${ }^{2)}$ \\ Magister Pendidikan Fisika, Program Pascasarjana, Universitas Ahmad Dahlan, Yogyakarta \\ Kampus 2, J1. Pramuka 42, Sidikan, Umbulharjo, Yogyakarta 55161, Indonesia \\ ${ }^{1)}$ muadinwasis59@gmail.com, ${ }^{2)}$ widodo@mp.uad.co.id
}

\begin{abstract}
Abstrak: Penelitian ini bertujuan untuk mengetahui adanya peningkatan prestasi siswa dalam pembelajaran fisika dengan lembar kerja siswa berbasis contextual teaching and learning (CTL). Jenis penelitian ini adalah penelitian pengembangan dengan subjek penelitian siswa kelas VIII SMP Muhammadiyah Pakem Yogyakarta tahun 2017/2018.Data yang diperoleh dianalisis menggunakan uji $\mathrm{t}$ pada taraf signifikan $5 \%$ dengan hasil sebesar $\mathrm{P}=0,000$, artinya ada perbedaan prestasi belajar kelas yang menggunakan LKS berbasis CTL dibanding dengan kelas dengan pembelajaran konvensional.Rata-rata nilai N-Gain diperoleh melalui data posttest dan pretest. Nilai rata-rata kelas kontrol sebesar 0,5462 sedangkan kelas eksperimen sebesar 0,6662. Hal ini menunjukkan bahwa penerapan LKS berbasis CTL yang telah dikembangkan berpengaruh positif untuk meningkatkan prestasi belajar fisika siswa kelas VIII sehingga LKS berbasis CTL tersebut dapat dikembangkan lebih luas.
\end{abstract}

Kata kunci: Pengembangan, Contextual Teaching and Learning (CTL), Prestasi belajar.

\section{PENDAHULUAN}

Pendidikan adalah salah satu aspek terpenting dalam majunya suatu negara. Pendidikan merupakan pembentuk karakter bangsa.Oleh karena itu, setiap warga negara memiliki hak untuk mendapatkan pendidikan yang layak. Dengan pendidikan dapat membuat kehidupan menjadi lebih sejahtera. Perkembangan zaman saat ini telah menuntut setiap negara untuk menciptakan sumber daya manusia yang dapat bersaing dalam kancah global. Dalam pasal 20 UU tahun 2003, pendidikan nasional berfungsi untuk mengembangkan kemampuan dan membentuk watak serta peradaban bangsa Indonesia dengan tujuan untuk mengembangkan potensi yang dimiliki peserta didik agar menjadi manusia yang berkualitas dengan ciri-ciri beriman dan bertaqwa kepada Tuhan YME, berakhlak mulia, sehat, beriman, cakap, kreatif, mandiri dan menjadi warga negara yang demokratis, serta bertanggungjawab.

Pembelajaran fisika sebagai dasar ilmu pengetahuan memegang peranan penting dalam perkembangan. Ilmu pengetahuan adalah salah satu standar bagi suatu bangsa dan negara yang maju dalam bidang teknologi. Penguasaan atas ilmu fisika oleh peserta didik diharapkan menjadi potensi sumberdaya manusia Indonesia. Peserta didik merupakan output yang mampu berperan serta dalam memajukan bangsa dan negara. Guru sebagai pelaksana utama pendidikan sangat menentukan peranannya. Pendekatan mengajar yang diterapkan dalam proses belajar mengajar merupakan salah satu faktor dominan yang menentukan keberhasilan belajar siswa. Semudah apapun materi pelajaran yang akan diajarkan, tidak akan berhasil maksimal jika pendekatan yang digunakan tidak tepat.

Lembar Kerja Siswa merupakan salah satu media/alat bantu pengajaran yang sering digunakan. Lembar kerja siswa yang digunakan seringkali tidak sesuai dengan pokok bahasan.Oleh karena itu, perlu dilakukan pembenahan dalam pembelajaran yang dapat mengaktifkan siswa, salah satunya dengan penerapan pendekatan Contextual Teaching and learning $(C T L)$ untuk meningkatkan daya kritis siswa. 
Contextual Teaching and Learning(CTL) adalah sebuah sistem belajar yang didasarkan pada filosofi bahwa seseorang pembelajar akan mampu menyerap materi pelajaran jika mereka dapat menangkap makna dari pelajaran tersebut. Jika siswa hanya diminta untuk berlatih dan belajar dalam waktu singkat sebelum ujian, maka dalam waktu singkat pula ia akan melupakan sebagian besar informasi yang didapat dari belajar kecuali jika informasi atau materi pelajaran merupakan titik tolak pembelajaran dengan pendekatan Contextual Teaching and Learning $(C T L)$.

Berdasarkan observasi yang dilakukan peneliti pada bulan Februari 2017di SMP Muhammadiyah Pakem Yogyakarta, diketahui bahwa hasil belajar fisika siswa belum memuaskan. Hal ini diketahui dari nilai siswa yang belum memenuhi KKM yang ditetapkan sekolah tersebut. Selain itu minat dan motivasi siswa juga kurang dalam memelajari fisika, misalnya siswa tidak antusias ketika guru menyampaikan materi dan memberi tugas. Bahkan masih ada siswa yang tidak mengerjakan tugas dan tidak membawa buku. Hal ini disinyalir karena beberapa faktor, misalnya karena cara penyampaian materi yang kurang menarik, media untuk menyampaikan materi kurang kreatif, dan contoh aplikasi konsep belum dijelaskan dalam kehidupan sehari-hari.

Dari hasil wawancara dengan guru mata pelajaran menyatakan bahwa dalam proses pembelajaran siswa belum terlibat secara aktif dan pembelajaran masih terpusat pada guru atau teacher center sehingga dapat dikatakan aktivitas siswa dalam pembelajaran masih rendah, terutama dalam hal mengemukakan pendapatnya tentang konsep yang dipelajari dan membuat sebuah kesimpulan dari konsep tersebut.Berdasarkan latar belakang di atas, peneliti tertarik untuk melakukan penelitian tentang "Pengembangan Lembar Kerja Siswa (LKS) fisika berbasis Contextual Teaching and Learning(CTL) untuk meningkatkan prestasi belajar siswa".Penelitian ini diharapkan dapat memberikan kontribusi dalam hal penggunaan lembar kerja siswa yang efektif untuk pembelajaran yang variatif.

\section{LANDASAN TEORI}

\subsection{Lembar Kerja Siswa}

Menurut Hendro dan Jenny (1992), LKS atau Lembar Kerja Siswa merupakan sarana pembelajaran yang dapat digunakan guru dalam meningkatkan keterlibatan atau aktivitas siswa dalam proses belajar mengajar. Pada umumnya, LKS berisi petunjuk praktikum, percobaan yang bisa dilakukan di rumah, materi untuk diskusi, Teka Teki Silang, tugas portofolio, dan soal-soal latihan, maupun segala bentuk petunjuk yang mampu mengajak siswa beraktivitas dalam proses pembelajaran.

Mengajar dengan menggunakan LKS ternyata semakin populer terutama pada masa dekade terakhir ini. Manfaat yang diperoleh dengan menggunakan LKS (Hendro dan Jenny, 1992) antara lain:

1) Memudahkan guru dalam mengelola proses belajar, misalnya mengubah kondisi belajar dari suasana "guru sentris" menjadi "siswa sentris".

2) Membantu guru mengarahkan siswanya untuk dapat menemukan konsep-konsep melalui aktivitasnya sendiri atau dalam kelompok kerja.

3) Dapat digunakan untuk mengembangkan ketrampilan proses, mengembangkan sikap ilmiah serta membangkitkan minat siswa terhadap alam sekitarnya.

4) Memudahkan guru memantau keberhasilan siswa untuk mencapai sasaran belajar.

\subsection{Contextual Teaching and Learning (CTL)}

Contextual Teaching and Learning (CTL) merupakan konsep belajar yang membantu guru mengaitkan antara materi yang diajarkan dengan situasi dunia nyata yang dialami siswa dan 
mendorong siswa membuat hubungan antara pengetahuan yang dimiliki dengan penerapannya dalam kehidupan siswa, sebagai anggota keluarga dan anggota masyarakat (Depdiknas, 2006:1).

Model pembelajaran kontekstual dapat juga dikatakan sebagai sebuah system yang merangsang otak untuk menyusun pola-pola yang mewujudkan makna. Contextual teaching and learning (CTL) adalah suatu system pengajaran yang cocok dengan otak yang menghasilkan makna dengan menghubungkan muatan akademis dengan konteks kehidupan sehari-hari siswa. Dengan memanfaatkan lingkungan, merangsang sel-sel saraf otak untuk memfokuskan diri pada konteks, dan hubungan-hubungan. (Elaine B. Johnson, 2006:57)

Ada tujuh komponen utama pembelajaran yang mendasari penerapan pembelajaran kontekstual di kelas yaitu sebagai berikut (Kusnandar, 2007:305)

1) Konstruktivisme. Konstruktivisme adalah landasan berfikir pembelajaran kontekstual yang menyatakan bahwa pengetahuan dibangun oleh manusia sedikit demi sedikit, yang hasilnya diperluas melalui konteks yang terbatas dan tidak sekonyong-konyong.

2) Menemukan (inquiry). Menemukan merupakan bagian inti dari kegiatan pembelajaran berbasis kontekstual yang berpendapat bahwa pengetahuan dan keterampilan yang diperoleh siswa diharapkan bukan hasil mengingat seperangkat fakta, tetapi hasil dari menemukan sendiri.

3) Bertanya (Questioning). Pengetahuan yang dimiliki seseorang selalu bermula dari bertanya. Bertanya merupakan strategi utama pembelajaran berbasis kontekstual.

4) Masyarakat Belajar (Learning Community). Masyarakat belajar pada dasarnya mengandung pengertian sebagai berikut : (1)Adanya kelompok belajar yang berkomunikasi untuk berbagi gagasan dan pengalaman. (2)Ada kerjasama untuk memecahkan masalah. (3)Pada umumnya hasil kerja kelompok lebih baik dari pada kerja secara individual. (4)Ada rasa tanggung jawab kelompok, semua anggota dalam kelompok mempunyai tanggung jawab yang sama. (5)Upaya membangun motivasi belajar bagi anak yang belum mampu. (6)Menciptakan situasi dan kondisi yang memungkinkan seorang anak belajar dengan anak lainnya. (7)Ada rasa tanggung jawab dan kerjasama untuk saling memberi dan menerima. (8)Ada fasilitator atau guru yang memandu proses belajar. (9)Harus ada komunikasi dua arah atau multi arah. (10)Ada kemauan untuk menerima pendapat yang lebih baik. (11)Ada kesediaan untuk menghargai pendapat orang lain. (12)Tidak ada kebenaran yang hanya satu saja. (13)Dominasi siswa yang pintar perlu diperhatikan agar yang lemah bisa pula berperan. (14)Siswa bertanya kepada teman-temannya.

5) Pemodelan (Modelling). Pemodelan artinya dalam sebuah pembelajaran keterampilan atau pengetahuan tertentu, ada model yang bisa ditiru.

6) Refleksi (Reflection). Refleksi adalah cara berfikir tentang apa yang baru dipelajari atau berfikir kebelakang tentang apa-apa yang sudah kita lakukan di masa yang lalu. Refleksi merupakan gambaran terhadap kegiatan atau pengetahuan yang baru saja diterima.

7) Penilaian yang sebenarnya (Authentic Assesment). Assesment adalah proses pengumpulan berbagai data yang bisa memberikan gambaran perkembangan belajar siswa. Gambaran perkembangan belajar siswa perlu diketahui oleh guru agar bisa memastikan bahwa siswa mengalami proses pembelajaran dengan benar.

\subsection{Kelebihan Contextual Teaching and Learning (CTL)}

1) Siswa dapat memahami konsep secara lebih mendalam terhadap suatu pokok bahasan. 
2) Merangsang daya berfikir yang imajinatif, tidak tersekat retorika tekstual dan komunikasi verbal yang selama ini ditunjukan oleh sistem dan penyelenggaraan pendidikan pada umumnya.

3) Siswa dapat secara eksploratif mengembangkan konsep yang dipahaminya karena pembelajaran dengan pendekatan Contextual Teaching and Learning (CTL) akan memupuk daya pemahaman konsep yaitu pemahaman yang mengakar (radikal). Bila anak sudah memahami konsep pelajaran, maka materi-materi pengembangannya akan mudah untuk dipelajari.

4) Pelajaran lebih mudah diingat karena pendekatan Contextual Teaching and Learning (CTL) lebih mengedepankan sisi discovery learning.

\subsection{Kelemahan Contextual Teaching and Learning (CTL)}

1) Guru yang tidak melakukan persiapan mengajar akan kesulitan dalam menerapkan pendekatan Contextual Teaching and Learning (CTL) di kelas.

2) Sekolah yang kurang mendukung sarana dan prasarananya seperti laboratorium, akan mengalami kesulitan dalam pelaksanaan pembelajaran dengan pendekatan Contextual Teaching and Learning (CTL)

\subsection{Prestasi Belajar}

Menurut Hamalik (2008) prestasi adalah kesempurnaan yang dicapai seseorang dalam berpikir, merasa dan berbuat. Sedangkan dalam Depdiknas (2006), prestasi adalah hasil yang telah dicapai dari yang telah dilakukan atau dikerjakan. Lebih lanjut, Suryabrata (2003) menjelaskan, prestasi adalah hasil yang dicapai dari suatu latihan, pengalaman didukung oleh kesadaran seseorang atau siswa untuk belajar. Dengan demikian prestasi belajar fisika bisa dimaknai sebagai hasil yang telah dicapai dari proses perubahan tingkah laku sebagai akibat pengalaman dan interaksi antara siswa dengan sumber-sumber belajar fisika yang hasilnya diwujudkan dalam bentuk nilai atau angka.

\section{METODE PENELITIAN}

Jenis penelitian ini adalah penelitian pengembangan. Penelitian dan pengembangan ini bertujuan untuk mengembangkan LKS fisika berbasis CTL dan mengetahui pengaruh penggunaan LKS terhadap hasil belajar siswa kelas VIII SMP Muhammadiyah Pakem. Langkah-langkah pelaksanaan penelitian dan pengembangan yang dikemukakan Borg dan Gall (2007) terdiri dari 10 langkah yaitu: 1. Research and information collecting, 2. Planning, 3. Develop premilinary form of product, 4. Preliminary field testing, 5. Main product revision, 6. Main field testing, 7. Operational product revision, 8. Operational field testing, 9. Final product revision, dan 10. Dissemination and implementation. Penelitian ini merupakan modifikasi dari Borg dan Gall yang hanya dilaksanakan sampai langkah ke-7. Modifikasi ini karena keterbatasan peneliti terkait waktu dan biaya.Populasi dalam penelitian ini adalah seluruh siswa VIII SMP Muhammadiyah Pakemtahun ajaran 2017/2018, yang berjumlah empat kelas.Adapun teknik pengambilan sampel untuk uji terbatas adalah Purposivesampling, sedangkan untuk uji lapangan menggunakan teknik cluster random sampling. Instrumen yang digunakan adalah tes pilihan ganda dan angket untuk mengetahui tanggapan siswa. Data diolah menggunakan data yang didapat dari uji N-Gain dan uji t (Arikunto, 2006).Sumber data diperoleh dari siswa kelas VIII SMP Muhammadiyah Pakem, serta validator yaitu 2 dosen ahli dan 2 guru fisika. 


\section{HASIL DAN PEMBAHASAN}

Validitas LKS berbasis Contextual Teaching and Learning (CTL)pada materi pokok Hukum Newtondiukur menggunakan angket.Hasil ujivaliditas LKS oleh 4 validator bernilai 3,46 dengan kualitas baik yang akan ditampilkan pada tabel 1 sebagai berikut.

Tabel 1. Hasil Uji Validitas LKS Berbasis CTL

\begin{tabular}{|c|c|c|c|c|c|c|c|c|}
\hline \multirow{2}{*}{ Aspek } & \multirow{2}{*}{ Indikator } & \multirow{2}{*}{ Bukti } & \multicolumn{4}{|c|}{ Validator } & \multirow{2}{*}{$\begin{array}{l}\text { Rata- } \\
\text { rata }\end{array}$} & \multirow{2}{*}{$\begin{array}{l}\text { Rata-rata } \\
\text { Total }\end{array}$} \\
\hline & & & 1 & 2 & 3 & 4 & & \\
\hline \multirow[t]{6}{*}{$\begin{array}{l}\text { A. } \\
\text { Tampilan }\end{array}$} & \multirow[t]{3}{*}{ 1. Cover } & $\begin{array}{l}\text { a. Menimbulkan suasana yang } \\
\text { menyenangkan }\end{array}$ & 3 & 2 & 4 & 3 & 3 & \multirow{21}{*}{3,46} \\
\hline & & b. Menimbulakan daya tarik & 3 & 2 & 4 & 3 & 3 & \\
\hline & & $\begin{array}{lccc}\text { c. } & \text { Komposisi } \\
\text { digunakan serasi } & \text { warna } & \text { yang } \\
\end{array}$ & 3 & 2 & 4 & 3 & 3 & \\
\hline & \multirow[t]{3}{*}{ 2. Design } & $\begin{array}{l}\text { a. Teks yang digunakan } \\
\text { terformat dengan baik }\end{array}$ & 3 & 3 & 3 & 4 & 3,25 & \\
\hline & & $\begin{array}{l}\text { b. Gambar yang digunakan } \\
\text { terstruktur dengan baik }\end{array}$ & 3 & 3 & 3 & 4 & 3,25 & \\
\hline & & c. Grafis terorganisir dengan baik & 3 & 3 & 3 & 4 & 3,25 & \\
\hline \multirow[t]{9}{*}{$\begin{array}{l}\text { B. Isi } \\
\text { Materi }\end{array}$} & \multirow{3}{*}{$\begin{array}{l}1 . \\
\text { Kebenaran } \\
\text { konsep } \\
\text { fisika }\end{array}$} & $\begin{array}{l}\text { a. Rumus yang digunakan } \\
\text { benar }\end{array}$ & 4 & 4 & 4 & 4 & 4 & \\
\hline & & $\begin{array}{lll}\text { b. Simbol-simbol yang } \\
\text { digunakan benar }\end{array}$ & 4 & 4 & 4 & 4 & 4 & \\
\hline & & $\begin{array}{l}\text { c. Soal-soal yang digunakan } \\
\text { sesuai dengan materi }\end{array}$ & 4 & 4 & 4 & 4 & 4 & \\
\hline & \multirow{3}{*}{$\begin{array}{l}2 . \\
\text { Kedalaman } \\
\text { konsep } \\
\text { fisika }\end{array}$} & $\begin{array}{l}\text { a. Materi yang digunakan } \\
\text { sesuai dengan kemampuan anak }\end{array}$ & 4 & 4 & 3 & 4 & 3,75 & \\
\hline & & $\begin{array}{l}\text { b. Materi yang digunakan } \\
\text { sesuai dengan perkembangan } \\
\text { jiwa anak }\end{array}$ & 4 & 4 & 3 & 4 & 3,75 & \\
\hline & & $\begin{array}{l}\text { c. Materi yang digunakan sesuai } \\
\text { dengan wawasan anak }\end{array}$ & 4 & 4 & 3 & 4 & 3,75 & \\
\hline & \multirow{3}{*}{$\begin{array}{l}\text { 3. Isi LKS } \\
\text { sesuai } \\
\text { dengan } \\
\text { Contextual } \\
\text { Teaching } \\
\text { and } \\
\text { Learning } \\
\text { (CTL) }\end{array}$} & $\begin{array}{l}\text { a. Memberi kesempatan kepada } \\
\text { siswa untuk membuat produk } \\
\text { fisika yang sederhana }\end{array}$ & 3 & 3 & 4 & 4 & 3,5 & \\
\hline & & $\begin{array}{l}\text { b. Menghubungkan ilmu } \\
\text { pengetahuan dan teknologi } \\
\text { dengan kehidupan sehari-hari }\end{array}$ & 3 & 3 & 4 & 4 & 3,5 & \\
\hline & & $\begin{array}{l}\text { c. Mengajak siswa aktif dalam } \\
\text { pembelajaran }\end{array}$ & 3 & 3 & 4 & 4 & 3,5 & \\
\hline \multirow[t]{6}{*}{ C. Bahasa } & \multirow{3}{*}{$\begin{array}{l}1 . \\
\text { Kejelasan } \\
\text { kalimat } \\
\text { yang } \\
\text { digunakan }\end{array}$} & $\begin{array}{l}\text { a. Kalimat tidak bermakna } \\
\text { ganda }\end{array}$ & 4 & 3 & 4 & 3 & 3,5 & \\
\hline & & $\begin{array}{l}\text { b. Kalimat yang digunakan } \\
\text { mudah dipahami }\end{array}$ & 4 & 3 & 4 & 3 & 3,5 & \\
\hline & & c. Kalimat yang digunakan jelas & 4 & 3 & 4 & 3 & 3,5 & \\
\hline & \multirow{3}{*}{$\begin{array}{l}2 . \\
\text { Kebakuan } \\
\text { kalimat } \\
\text { yang }\end{array}$} & a. Kalimat sesuai dengan EYD & 4 & 3 & 4 & 3 & 3,5 & \\
\hline & & $\begin{array}{l}\text { b. Kalimat yang digunakan } \\
\text { tidak ambigu }\end{array}$ & 4 & 3 & 4 & 3 & 3,5 & \\
\hline & & c. Kalimat yang digunakan & 4 & 3 & 4 & 3 & 3,5 & \\
\hline
\end{tabular}




\begin{tabular}{|l|l|l|l|l|l|l|l|l|}
\hline digunakan & mempunyai struktur yang jelas & & & & & \\
${$\cline { 2 - 5 }$} \begin{array}{l}\text { yang } \\
\text { digunakan } \\
\text { dalam LKS } \\
\text { tepat }\end{array} }$ & $\begin{array}{l}\text { a. Bahasa yang digunakan } \\
\text { mengajak siswa interaktif }\end{array}$ & 3 & 3 & 4 & 4 & 3,5 \\
\cline { 2 - 6 } Bahasa yang digunakan & 3 & 3 & 4 & 4 & 3,5 \\
\cline { 2 - 8 } & $\begin{array}{l}\text { c. Bahasa yang digunakan sesuai } \\
\text { dengan kedewasaan anak }\end{array}$ & 3 & 3 & 4 & 4 & 3,5 \\
\hline
\end{tabular}

Pada tahap uji terbatas, dihasilkan respon 11 siswa yang ditampilkan dalam tabel 2 dengan keterangan sebagai berikut:

SS = Sangat setuju, $\mathrm{S}=$ Setuju, TS = Tidak setuju, STS = Sangat tidak setuju

$$
\Sigma \text { NRS SS }=\Sigma \mathrm{R} \times 4
$$

$\Sigma$ NRS S $=\Sigma \mathrm{R} \times 3$

$\Sigma$ NRS TS $=\Sigma \mathrm{R} \times 2$

$\Sigma$ NRS STS $\quad=\Sigma \mathrm{R} \times 1$

$\%$ NRS $=$ Persentase nilai respon siswa

$$
=\frac{\sum N R S}{\text { NRS maksimum }} \times 100 \%
$$

$\Sigma \mathrm{R}=$ Jumlah responden

$\Sigma \mathrm{NRS}=\mathrm{NRS} \mathrm{SS}+\mathrm{NRS} \mathrm{S}+\mathrm{NRS}$ TS + NRS STS

NRS maksimum $=$ jumlah siswa $\mathrm{x} 4$

Rata-rata $=\frac{\sum \% N R S}{15}$

\begin{tabular}{|c|c|c|c|c|c|c|c|c|c|}
\hline \multirow[t]{2}{*}{ Aspek } & \multirow{2}{*}{$\begin{array}{l}\text { Indikato } \\
\mathrm{r}\end{array}$} & \multirow[t]{2}{*}{ Bukti } & \multicolumn{4}{|c|}{$\sum \mathrm{R}$} & \multirow{2}{*}{$\begin{array}{l}\text { JmlSis } \\
\text { wa }\end{array}$} & \multirow{2}{*}{$\begin{array}{l}\% \\
\text { NRS }\end{array}$} & \multirow[t]{2}{*}{ Kriteria } \\
\hline & & & $\begin{array}{l}\mathrm{S} \\
\mathrm{S}\end{array}$ & $\mathrm{S}$ & $\begin{array}{l}\mathrm{T} \\
\mathrm{S}\end{array}$ & $\begin{array}{l}\text { ST } \\
\text { S }\end{array}$ & & & \\
\hline \multirow[t]{6}{*}{$\begin{array}{l}\text { A. } \\
\text { Tampilan }\end{array}$} & \multirow[t]{3}{*}{ 1. Cover } & $\begin{array}{l}\text { a. Menimbulkan } \\
\text { suasana yang } \\
\text { menyenangkan }\end{array}$ & 7 & 4 & & & 11 & $91 \%$ & $\begin{array}{l}\text { Sangat } \\
\text { kuat }\end{array}$ \\
\hline & & $\begin{array}{l}\text { b. Menimbulakan } \\
\text { daya tarik }\end{array}$ & 4 & 6 & 1 & & 11 & $82 \%$ & $\begin{array}{l}\text { Sngat } \\
\text { kuat }\end{array}$ \\
\hline & & $\begin{array}{l}\text { c. Komposisi warna } \\
\text { yang digunakan } \\
\text { serasi }\end{array}$ & 6 & 5 & & & 11 & $89 \%$ & $\begin{array}{l}\text { Sangat } \\
\text { Kuat }\end{array}$ \\
\hline & \multirow[t]{3}{*}{$\begin{array}{l}2 . \\
\text { Design }\end{array}$} & 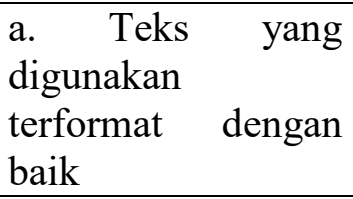 & 6 & 3 & 2 & & 11 & $84 \%$ & $\begin{array}{l}\text { Sangat } \\
\text { kuat }\end{array}$ \\
\hline & & $\begin{array}{ll}\text { b. Gambar yang } \\
\text { digunakan } \\
\text { terstruktur dengan } \\
\text { baik }\end{array}$ & 6 & 5 & & & 11 & $89 \%$ & $\begin{array}{l}\text { Sangat } \\
\text { Kuat }\end{array}$ \\
\hline & & $\begin{array}{lr}\text { c. } & \text { Grafis } \\
\text { terorganisir } & \text { dengan } \\
\text { baik } & \end{array}$ & 7 & 3 & 1 & & 11 & $89 \%$ & $\begin{array}{l}\text { Sangat } \\
\text { Kuat }\end{array}$ \\
\hline C. Bahasa & $\begin{array}{l}1 . \\
\text { Kejelasa }\end{array}$ & $\begin{array}{l}\text { a. Kalimat tidak } \\
\text { bermakna ganda }\end{array}$ & 3 & 7 & 1 & & 11 & $80 \%$ & Kuat \\
\hline
\end{tabular}

Tabel 2. Angket Respon Siswa 


\begin{tabular}{|c|c|c|c|c|c|c|c|c|}
\hline & $\mathrm{n}$ & & & & & & & \\
\hline & $\begin{array}{l}\text { kalimat } \\
\text { yang } \\
\text { digunak }\end{array}$ & $\begin{array}{l}\text { b. Kalimat yang } \\
\text { digunakan mudah } \\
\text { dipahami }\end{array}$ & 5 & 6 & & 11 & $86 \%$ & $\begin{array}{l}\text { Sangat } \\
\text { kuat }\end{array}$ \\
\hline & & $\begin{array}{l}\text { c. Kalimat yang } \\
\text { digunakan jelas }\end{array}$ & 6 & 5 & & 11 & $89 \%$ & $\begin{array}{l}\text { Sangat } \\
\text { Kuat }\end{array}$ \\
\hline & $\begin{array}{l}2 . \\
\text { Kebaku }\end{array}$ & $\begin{array}{l}\text { a. Kalimat sesuai } \\
\text { dengan EYD }\end{array}$ & 4 & 4 & 3 & 11 & $77 \%$ & Kuat \\
\hline & $\begin{array}{l}\text { an } \\
\text { kalimat } \\
\text { yang }\end{array}$ & $\begin{array}{ll}\text { b. Kalimat yang } \\
\text { digunakan } \\
\text { ambigu }\end{array}$ & 3 & 7 & 1 & 11 & $80 \%$ & Kuat \\
\hline & $\begin{array}{l}\text { digunak } \\
\text { an }\end{array}$ & $\begin{array}{l}\text { c. Kalimat yang } \\
\text { digunakan } \\
\text { mempunyai } \\
\text { struktur yang jelas }\end{array}$ & 4 & 5 & 2 & 11 & $80 \%$ & $\begin{array}{l}\text { Sangat } \\
\text { kuat }\end{array}$ \\
\hline & $\begin{array}{l}3 . \\
\text { Bahasa } \\
\text { yang } \\
\text { digunak }\end{array}$ & $\begin{array}{ll}\text { a. Bahasa } & \text { yang } \\
\text { digunakan } & \\
\text { mengajak } & \text { siswa } \\
\text { interaktif } & \end{array}$ & 7 & 4 & & 11 & $91 \%$ & $\begin{array}{l}\text { Sangat } \\
\text { Kuat }\end{array}$ \\
\hline & $\begin{array}{l}\text { an } \\
\text { dalam }\end{array}$ & $\begin{array}{l}\text { b. Bahasa yang } \\
\text { digunakan menarik }\end{array}$ & 6 & 5 & & 11 & $89 \%$ & $\begin{array}{l}\text { Sangat } \\
\text { kuat }\end{array}$ \\
\hline & $\begin{array}{l}\text { LKS } \\
\text { tepat }\end{array}$ & $\begin{array}{l}\text { c. Bahasa yang } \\
\text { digunakan sesuai } \\
\text { dengan kedewasaan } \\
\text { anak }\end{array}$ & 5 & 5 & 1 & 11 & $84 \%$ & $\begin{array}{l}\text { Sangat } \\
\text { Kuat }\end{array}$ \\
\hline Rata-rata & & & & & & & $85 \%$ & $\begin{array}{l}\text { Sangat } \\
\text { Kuat }\end{array}$ \\
\hline
\end{tabular}

Berdasarkan tabel di atas diperoleh persentase keberhasilan tindakan $85 \%$, sehingga masuk dalam kategori sangat kuat.

Prestasi belajar siswa diukur dengan tes yang menggunakan 30 soal pilihan ganda. Tes pilihan ganda ini diberikan ketika pretest dan posttest. Berikut ini data pretest, posttest dan NGainuntuk kelas eksperimen dan kelas kontrol:

Tabel 3. Data pretest, posttest dan N-Gain

\begin{tabular}{lcllll}
\hline \multirow{2}{*}{ Komponen } & Grup kelas & $\mathbf{N}$ & Min & Maks & Rata-rata \\
\hline \multirow{2}{*}{ Pretest } & Eksperimen & 37 & 40 & 66,7 & 46,9 \\
& Kontrol & 37 & 23,3 & 60 & 43,9 \\
\hline \multirow{2}{*}{ Posttest } & Eksperimen & 37 & 76,7 & 96,7 & 81,6 \\
& Kontrol & 37 & 53,3 & 90 & 73,9 \\
\hline \multirow{2}{*}{ Gain } & Eksperimen & 37 & 0,59 & 0,91 & 0,67 \\
& Kontrol & 37 & 0,39 & 0,75 & 0,55 \\
\hline
\end{tabular}

Berdasarkan hasil uji homogenitas diperoleh $\mathrm{F}=0,277(\mathrm{p}=0,600)$ karena $\mathrm{p}>0.05$ maka dapat dikatakan tidak ada perbedaan varians pada data prestasi belajar kelas kontrol dan kelas eksperimen. Sedangkan pada uji t terlihat nilai signifikansi $(p=0,000)$ karena $p<0,05$ artinya ada perbedaan prestasi belajar yang sangat signifikan antara kelas yang menggunakan LKS berbasis CTL dibanding kelas yang menggunakan pembelajaran konvensional. 
Selanjutnya, untuk mengetahui prestasi belajar kelompok mana yang lebih tinggi, dapat dilihat dari nilai mean masing-masing kelompok. Nilai mean untuk kelas kontrol sebesar 0,5462 sedangkan kelas eksperimen sebesar 0,6662. Hal ini menunjukkan bahwa mean kelas eksperimen lebih tinggi daripada kelas kontrol. berarti bahwa kelas yang menggunakan LKS berbasis CTL lebih baik dibanding kelas yang menggunakan pembelajaran konvensional.

\section{KESIMPULAN}

Berdasarkan data yang diperoleh dapat ditarik kesimpulan sebagai berikut:

1. Hasil pengembangan LKS berbasis CTL layak digunakan untuk pembelajaran fisika SMP kelas VIII.

2. Pada penelitian pengembangan ini diperoleh perbedaan prestasi belajar siswa dalam pembelajaran fisika dengan lembar kerja siswa berbasis Contextual Teaching and Learning (CTL)dibanding dengan pembelajaran konvensional.

\section{DAFTAR PUSTAKA}

Arikunto, Suharsimi.,dkk. 2014. Dasar-Dasar Evaluasi Pendidikan Edisi revisi.Jakarta: Bumi Aksara.

Departemen Pendidikan Nasional, 2006. Kamus Besar Bahasa Indonesia, Jakarta : Pusat Bahasa Balai Pustaka.

Elaine B. Johnson. 2006. Contextual Teaching \& Learning: Menjadikan Kegiatan Belajar Mengajar Mengasyikkan. Bandung: MLC.

Hamalik, O. 2008. Pendekatan Pengajaran Berdasarkan Pendekatan Sistem. Jakarta : Bumi Aksara.

Khabibah, Siti. 2006. Pengembangan Model Pembelajaran Matematika Dengan Soal Terbuka Untuk Kreatifitas Siswa SD. Disertasi tidak dipublikasikan. Surabaya : UNESA.

Kusnandar. 2007. Guru Profesional Implementasi, Kurikulum Tingkat Satuan Pendidikan (KTSP) dan Sukses Dalam Sertifikasi Guru, Jakarta : PT Rajagrafindo Persada.

Prasetyo, Wahyhu. Pengembangan Lembar Kegiatan Siswa (Lks) Dengan Pendekatan Pmr Pada Materi Lingkaran Di Kelas Viii Smpn 2 Kepohbaru Bojonegoro.Surabaya : UNESA.

Suryabrata, S. 2003. Psikologi Belajar I. Jakarta: CV Rajawali.

Hendro, D. dan Jenny R. E. K. 1992. Pendidikan IPA II. Jakarta: Depdikbud. 